\title{
ESTUDO PRELIMINAR DE TRATABILIDADE DO LIXIVIADO DO ATERRO SANITÁRIO DE LUANDA, ANGOLA; PROCESSO DE FENTON
}

\author{
R. J. E. MARTINS ${ }^{1,2}$ e R. A. R. BOAVENTURA ${ }^{2}$ \\ ${ }^{1}$ Instituto Politécnico de Bragança, Escola Superior de Tecnologia e de Gestão, Departamento de \\ Tecnologia Química e Biológica \\ ${ }^{2}$ Universidade do Porto, Laboratory of Separation and Reaction Engineering (LSRE), Departamento \\ de Engenharia Química \\ E-mail para contato: rmartins@ipb.pt
}

\begin{abstract}
RESUMO - O lixiviado de um aterro sanitário resulta da percolação de água das chuvas e dos processos de degradação dos resíduos; recolhido pelo sistema de drenagem não deve ser lançado diretamente no meio hídrico por apresentar elevado potencial poluidor. É prioritário o tratamento adequado, reduzindo a carga orgânica, com o objetivo de cumprir os padrões de emissão de efluentes e desta forma garantir a qualidade da saúde pública. Neste estudo foi caracterizado o lixiviado do Aterro Sanitário dos Mulenvos, e realizado um estudo preliminar sobre a eficiência do processo Fenton (POA), na remoção da matéria orgânica (expressa como DQO). Foram avaliadas/selecionadas as condições de operação adequadas para o processo (temperatura, $\mathrm{pH}$, dosagem de $\mathrm{H}_{2} \mathrm{O}_{2}$ e razão $\mathrm{H}_{2} \mathrm{O}_{2}: \mathrm{Fe}^{2+}$ ).
\end{abstract}

\section{INTRODUÇÃO}

Nos anos mais recentes tem ocorrido uma grande explosão demográfica, que aliada a uma procura crescente de bens de consumo, em especial nos países em desenvolvimento, levou a que as indústrias gerassem uma grande quantidade de resíduos. Grande parte são altamente poluidoras e se os resíduos não são sujeitos a tratamento adequado, representam um grande risco para o meio ambiente. Consequentemente os meios hídricos, recetores dos efluentes industriais e urbanos e de efluentes resultantes da deposição de resíduos sólidos, estão com a qualidade cada vez mais comprometida, representando um sério risco para a saúde humana.

O método de tratamento e disposição de resíduos sólidos urbanos, mais simples e barato, é o de aterro sanitário (EEA, 1998). Nos países sub desenvolvidos e em desenvolvimento, praticamente $100 \%$ dos resíduos gerados têm como destino final a deposição no solo, sendo pouco provável uma alteração a curto prazo (Lima, 2006), pratica que vem sendo ultimamente implementada em Angola. Esta opção tem sido a preferida, mesmo em países desenvolvidos, onde há uma forte cultura ambiental associada à reciclagem, minimização, reutilização e incineração de resíduos (Allen, 2003). 


\section{9 a 22 de outubro de 2014 \\ Florianópolis/SC}

Os aterros sanitários configuram-se como sistemas biológicos predominantemente anaeróbios, onde ocorre a conversão da matéria orgânica em biogás (metano e dióxido de carbono) e a formação de lixiviados. Sendo ambos altamente poluentes, um correto e eficaz tratamento deve ser uma das prioridades na gestão de aterros. Os lixiviados apresentam uma elevada heterogeneidade e variabilidade dos parâmetros físico-químicos e biológicos, ao longo do tempo, o que torna difícil a implementação de processos de tratamento eficientes. Para o tratamento de lixiviados são utilizados vários processos como o biológico, recirculação do lixiviado através do aterro, físico-químico entre outros, sendo os processos biológicos os mais empregados (Goi et al., 2010). Contudo, a presença de compostos recalcitrantes inviabiliza a utilização isolada destes tratamentos, donde surgem os processos oxidativos avançados (POA) como etapa de pré tratamento para que se torne eficaz um tratamento biológico a jusante (Silva et al., 2006).

Os POA envolvem a geração e uso "in situ" de agentes oxidantes fortes, como o radical hidroxilo, que possui um potencial de oxidação que o torna apto para reagir com compostos orgânicos e promover a sua completa mineralização a $\mathrm{CO}_{2}$, água e ácidos minerais. São agentes promissores para remoção de poluentes refratários quando os processos convencionais, nomeadamente os processos biológicos, não permitem atingir a eficiência de remoção de determinado poluente (Ding e Guan, 2013).

O objetivo principal deste estudo foi caracterizar e avaliar a tratabilidade do lixiviado do Aterro Sanitário dos Mulenvos (Luanda-Angola) por um processo de oxidação química com reagente de Fenton. Como objetivos específicos são de referir: (1) Caracterização físico-química do lixiviado do Aterro Sanitário dos Mulenvos; (2) Avaliação e seleção das condições de operação adequadas para o processo Fenton (temperatura, $\mathrm{pH}$, dosagem de $\mathrm{H}_{2} \mathrm{O}_{2}$ e razão $\mathrm{H}_{2} \mathrm{O}_{2}: \mathrm{Fe}^{2+}$ ) para reduzir a concentração de matéria orgânica e obter um efluente com uma biodegradabilidade (expressa pela razão $\left.\mathrm{DBO}_{5} / \mathrm{DQO}\right)$ aceitável para posterior tratamento biológico.

\section{MATERIAIS E MÉTODOS}

\subsection{Aterro Sanitário dos Mulenvos}

O Aterro Sanitário dos Mulenvos situa-se na região sudeste da cidade de Luanda, Município de Viana, em Angola, e ocupa uma área com um perímetro de aproximadamente $7 \mathrm{~km}$. O clima é tropical úmido, a que correspondem duas estações bem definidas: uma estação quente e com intensa pluviosidade e outra fria e úmida. A temperatura anual média é de $27^{\circ} \mathrm{C}$.

\subsection{Amostras}

As amostras de lixiviado usadas no estudo foram recolhidas à entrada da primeira lagoa de evaporação do Aterro Sanitário (Figura 1).

Foram usados recipientes de $20 \mathrm{~L}$ em polietileno (PEAD) para transporte das amostras de lixiviado até ao laboratório, sendo aqui transferido para frascos de PEAD com capacidade de $5 \mathrm{~L}$ e previamente lavados com solução de ácido clorídrico a 10\% e água desionizada. As amostras foram conservadas a 
$4^{\circ} \mathrm{C}$ até à sua utilização, sendo que aquelas usadas para determinação de metais tóxicos foram acidificadas a $\mathrm{pH}<2\left(\mathrm{HNO}_{3}\right)$. A amostragem foi realizada de acordo com o descrito no manual Standard Methods for the Examination of Water and Wastewater (APHA, 2012).

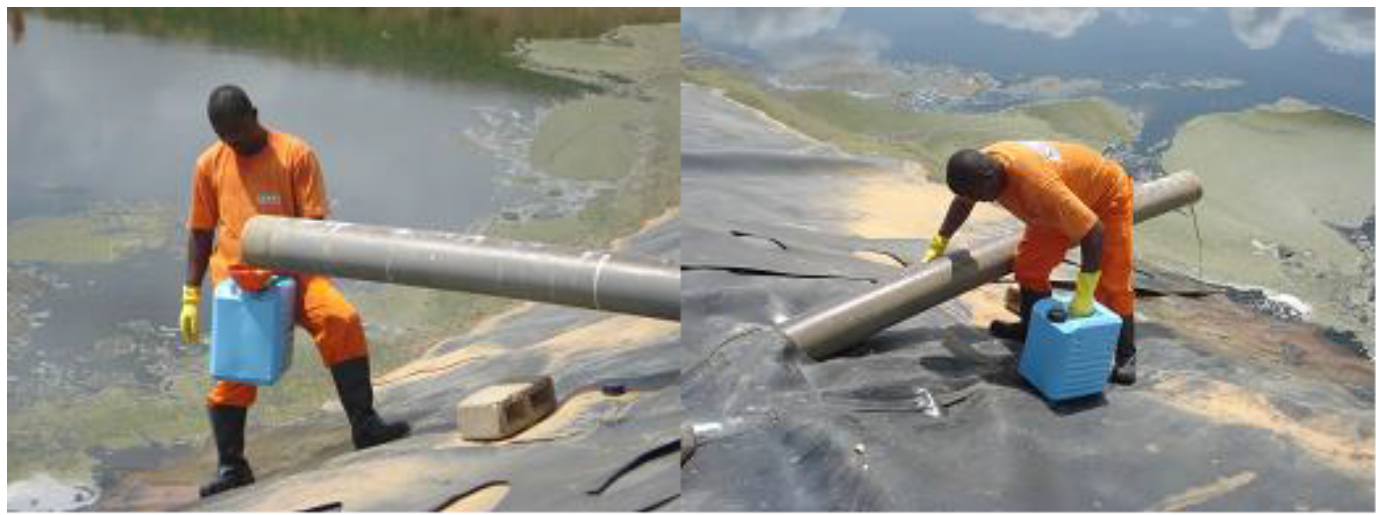

Figura 1 - Recolha das amostras de lixiviado bruto no Aterro Sanitário dos Mulenvos.

\subsection{Caracterização Analítica do Lixiviado}

$\mathrm{Na}$ caracterização físico-química do lixiviado foram determinados, de acordo com o Standard Methods for The Examination of Water and Wastewater (APHA, 2012), os seguintes parâmetros: $\mathrm{pH}$, Alcalinidade, Sólidos Totais, Sólidos Voláteis, Demanda Química de Oxigénio (DQO), Demanda Bioquímica de Oxigénio (DBO), Azoto Total e Fósforo Total. Foi ainda determinado um conjunto de elementos metálicos: alumínio, ferro, cádmio, crómio, cobre, chumbo, níquel e zinco.

Após a realização dos ensaios experimentais, usando como tratamento o Processo de Fenton, foram determinados novamente todos os parâmetros anteriormente referidos.

\subsection{Protocolo Experimental}

As experiências laboratoriais consistiram na caracterização físico-química do lixiviado bruto, no estudo da tratabilidade do mesmo usando o reagente de Fenton $\left(\mathrm{H}_{2} \mathrm{O}_{2}+\mathrm{FeSO}_{4}\right)$ e determinação das condições ótimas para realização do processo (temperatura, $\mathrm{pH}$, dosagem de $\mathrm{H}_{2} \mathrm{O}_{2}$ e razão $\mathrm{H}_{2} \mathrm{O}_{2}: \mathrm{Fe}^{2+}$ ) e na caracterização do efluente tratado.

\subsection{Estudo de Tratabilidade com o Reagente de Fenton}

O processo de oxidação utilizando o reagente de Fenton foi realizado num reator de vidro, com a capacidade de $600 \mathrm{~mL}$, que continha $100 \mathrm{~mL}$ de amostra. Foi adicionado peróxido de hidrogénio $\left(\mathrm{H}_{2} \mathrm{O}_{2}\right)$ com uma concentração $30 \%(\mathrm{p} / \mathrm{p})$. A densidade da solução é de $1,11 \mathrm{~g} / \mathrm{cm}^{3}$.

As variáveis estudadas no tratamento do lixiviado pelo processo Fenton incluem o $\mathrm{pH}$, concentração de $\mathrm{H}_{2} \mathrm{O}_{2}$, concentração de $\mathrm{Fe}(\mathrm{II})$ e tempo de reação. 
$\mathrm{Na}$ Figura 2 encontra-se uma representação esquemática da montagem experimental do processo Fenton.

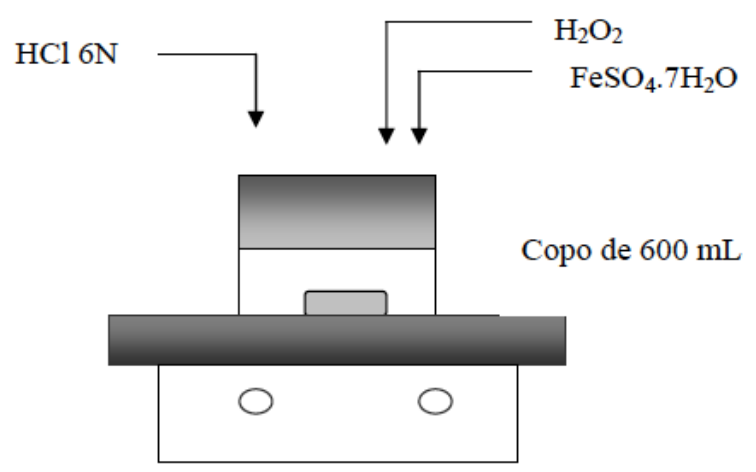

Agitador magnético

Figura 2 - Montagem experimental do processo Fenton.

Os ensaios foram conduzidos sob agitação constante e à temperatura ambiente $\left(25 \pm 2^{\circ} \mathrm{C}\right)$. Começou por se estudar a influência do $\mathrm{pH}$, na gama 2,5 a 3,5. De seguida estudou-se o efeito da concentração de $\mathrm{H}_{2} \mathrm{O}_{2}$, entre 3 e $12 \mathrm{~g} / \mathrm{L}$, e finalmente o efeito da concentração de $\mathrm{Fe}(\mathrm{II})$, entre cerca de 0,4 e 1,5 g/L. Nestes dois últimos conjuntos de experiências o valor do $\mathrm{pH}$ foi ajustado a 2,5.

Deixou-se prosseguir a reação por 20 minutos e depois de um período de decantação de 30 minutos foram retiradas amostras do sobrenadante para determinação da Demanda Química de Oxigénio (DQO). A paragem da reação foi feita por elevação do pH até $10 \mathrm{com} \mathrm{NaOH} \mathrm{10N.}$

\section{RESULTADOS E DISCUSSÃO}

\subsection{Caracterização do Lixiviado Bruto do Aterro Sanitário de Mulenvos}

Os resultados da caracterização do lixiviado bruto do Aterro dos Mulenvos, recolhido à entrada da primeira lagoa de evaporação, encontram-se na Tabela 1, bem como alguns parâmetros estatísticos para um nível de probabilidade de $95 \%$.

As características dos lixiviados de aterros sanitários variam em função de fatores como: composição do resíduo, topografia do local, clima, temperatura, tipo de solo, regime de pluviosidade e idade do aterro. No presente trabalho a $\mathrm{DBO}_{5}$ e DQO apresentaram valores médios de 2030 e 6450 $\mathrm{mg} \mathrm{O}_{2} / \mathrm{L}$, respetivamente. A razão $\mathrm{DBO}_{5} / \mathrm{DQO}$ apresenta um valor de 0,32 , indicativo de que o lixiviado contém alguma matéria orgânica biodegradável, mas que é significativo o seu conteúdo em compostos recalcitrantes (substâncias húmicas). Face a estes resultados é necessário efetuar o tratamento do lixiviado por forma a cumprir com os limites de emissão de descarga no meio receptor (no aterro é aplicada a legislação Brasileira), sendo que a via adequada será um tratamento de oxidação. 
Tabela 1 - Características do lixiviado bruto do Aterro Sanitário dos Mulenvos

\begin{tabular}{|c|c|c|c|}
\hline Parâmetro & Média & Desvio padrão (S) & Intervalo de confiança \\
\hline Temperatura, ${ }^{\circ} \mathrm{C}$ & 28,2 & -- & -- \\
\hline $\mathrm{pH}$ & 8,71 & $21,4 \times 10^{-2}$ & $8,49-8,94$ \\
\hline Condutividade, $\mathrm{mS} . \mathrm{cm}^{-1}$ & 23,3 & $11,7 \times 10^{-2}$ & $23,2-23,4$ \\
\hline Salinidade, g KCl. $\mathrm{kg}^{-1}$ & 14,0 & $5,2 \times 10^{-2}$ & $14,0-14,1$ \\
\hline Alcalinidade T., $\mathrm{mg} \mathrm{CaCO}_{3} \cdot \mathrm{L}^{-1}$ & 6400 & & 6400 \\
\hline $\mathrm{DBO}_{5}, \mathrm{mg} \mathrm{O}_{2} \cdot \mathrm{L}^{-1}$ & 2030 & $1,72 \times 10^{-2}$ & $1817-2244$ \\
\hline $\mathrm{DQO}, \mathrm{mg} \mathrm{O}_{2} \cdot \mathrm{L}^{-1}$ & 6450 & $4,08 \times 10^{-2}$ & $6136-6764$ \\
\hline $\mathrm{SDT}, \mathrm{mg} \cdot \mathrm{L}^{-1}$ & 11810 & $51,6 \times 10^{-2}$ & $11810-11811$ \\
\hline $\mathrm{ST}, \mathrm{mg} \cdot \mathrm{L}^{-1}$ & 13360 & $0,19 \times 10^{-2}$ & $13340-13380$ \\
\hline $\mathrm{SV}, \mathrm{mg} \cdot \mathrm{L}^{-1}$ & 3836 & $0,56 \times 10^{-2}$ & $3777-3894$ \\
\hline Nitratos, $\mathrm{mg} \mathrm{NO}_{3} \cdot \mathrm{L}^{-1}$ & 77,5 & & 77,5 \\
\hline Azoto Amon., $\mathrm{mg} \mathrm{NH}_{4} \cdot \mathrm{L}^{-1}$ & 1864 & & 1864 \\
\hline Azoto Total, $\mathrm{mg} \mathrm{N} . \mathrm{L}^{-1}$ & 2411 & $2,0 \times 10^{-2}$ & $2089-2732$ \\
\hline Fósforo Total, mg P.L $\mathrm{L}^{-1}$ & 3,41 & $15,3 \times 10^{-2}$ & $3,22-3,59$ \\
\hline
\end{tabular}

Relativamente ao teor de metais tóxicos, do conjunto analisado ( $\mathrm{Al}, \mathrm{Fe}, \mathrm{Cd}, \mathrm{Cr}, \mathrm{Cu}, \mathrm{Pb}, \mathrm{Ni}$ e $\mathrm{Zn}$ ), todos cumprem com os valores estabelecidos na legislação, com exceção do ferro que registou um teor de $7,42 \mathrm{mg} / \mathrm{L}$.

\subsection{Estudo da Tratabilidade com o Reagente de Fenton}

Efeito do $\mathrm{pH}$ : Os ensaios foram realizados para valores de $\mathrm{pH}$ no intervalo 2,5 a 3,5 e mantendo as seguintes condições operatórias: volume de lixiviado de $100 \mathrm{~mL}$; DQO inicial de $6450 \mathrm{mg} \mathrm{O} / \mathrm{L}$; temperatura de $25 \pm 2^{\circ} \mathrm{C}$; concentração de $\mathrm{H}_{2} \mathrm{O}_{2} 1,5,3$ e $6 \mathrm{~g} / \mathrm{L}$; concentração de $\mathrm{FeSO}_{4} \cdot 7 \mathrm{H}_{2} \mathrm{O}$ de 2,72 $\mathrm{g} / \mathrm{L}$; velocidade de agitação de $150 \mathrm{rpm}$.

Para um tempo de reação de 20 minutos seguido de um período de decantação de 30 minutos, foi determinada a DQO do sobrenadante, em triplicado, e calculadas as respetivas percentagens de remoção (Figura 3).

Da Figura 3 constata-se que a percentagem de remoção de DQO registou um aumento com a razão $\mathrm{H}_{2} \mathrm{O}_{2}: \mathrm{Fe}(\mathrm{II})$, sendo o efeito do $\mathrm{pH}$ na gama 2,5 a 3,5 praticamente sem significado. Contudo, para a razão $\mathrm{H}_{2} \mathrm{O}_{2}: \mathrm{Fe}(\mathrm{II})=10,91$ registou-se uma remoção ligeiramente superior a $\mathrm{pH} 2,5(65 \%)$, face aos $60 \%$ para os restantes valores de $\mathrm{pH}$. Neste ensaio verificou-se que no fím do período de reação o $\mathrm{pH}$ registava um valor em torno de 1,8 , abaixamento provavelmente devido à fragmentação do material orgânico em ácidos orgânicos. Para a totalidade das experiências foi registado um aumento da temperatura, dos $25 \pm 2^{\circ} \mathrm{C}$ para os $30 \pm 3^{\circ} \mathrm{C}$, o que confirma o caráter exotérmico da reação.

Foi realizado outro ensaio para a mesma razão $\mathrm{H}_{2} \mathrm{O}_{2}: \mathrm{Fe}(\mathrm{II})$, usando contudo quantidades diferentes de peróxido de hidrogénio e de sulfato ferroso: volume de lixiviado de $100 \mathrm{~mL}$; DQO inicial de $6450 \mathrm{mg} \mathrm{O} / \mathrm{L}$; temperatura de $25 \pm 2^{\circ} \mathrm{C}$; concentração de $\mathrm{H}_{2} \mathrm{O}_{2} 4,5$ e $6 \mathrm{~g} / \mathrm{L}$; concentração de 
$\mathrm{FeSO}_{4} .7 \mathrm{H}_{2} \mathrm{O}$ de 2,03 e 3,63 g/L; velocidade de agitação de 150 rpm.

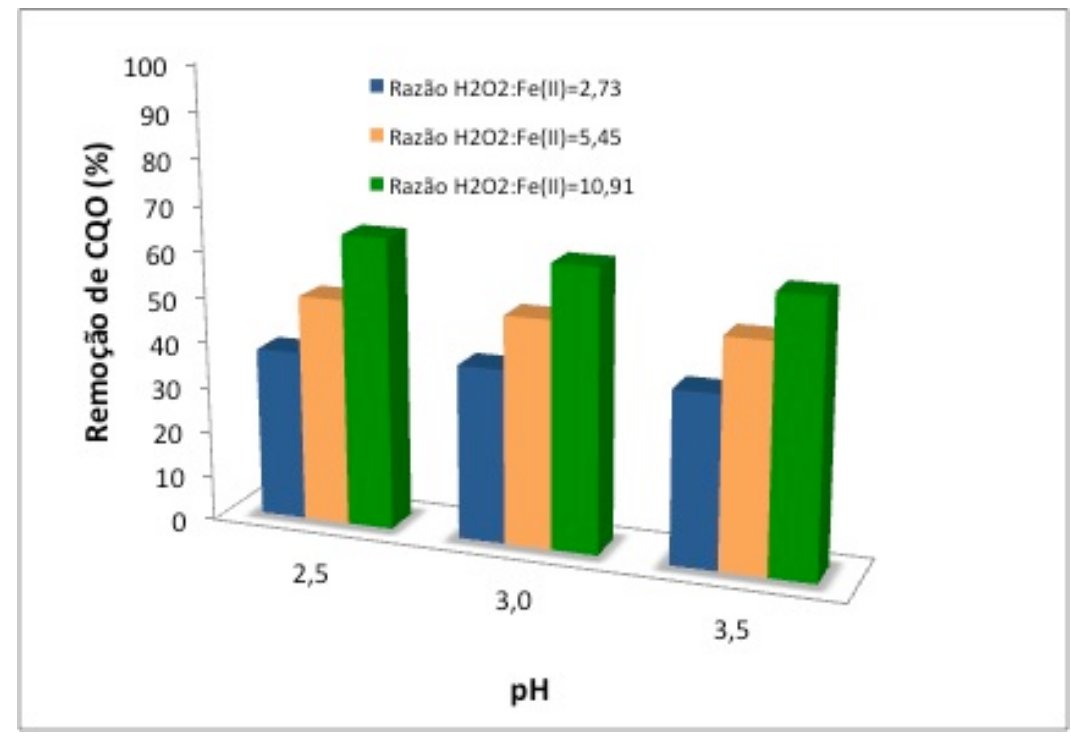

Figura 3 - Efeito do pH na remoção de DQO variando a razão $\mathrm{H}_{2} \mathrm{O}_{2}: \mathrm{Fe}(\mathrm{II})$.

Na Tabela 2 encontram-se os resultados obtidos para a remoção da DQO mantendo constante a razão $\mathrm{H}_{2} \mathrm{O}_{2}: \mathrm{Fe}(\mathrm{II})=10,9 ;$ o aumento das concentrações do peróxido de $(4,5$ para $6,0 \mathrm{~g} / \mathrm{L})$ e do ião ferro $(0,41$ para $0,55 \mathrm{~g} / \mathrm{L})$ não se traduziu em qualquer incremento da remoção da DQO para pH 3,0 e 3,5. A percentagem de remoção da DQO obtida para $\mathrm{pH} 2,5$ registou um melhor resultado para concentrações mais baixas de $\mathrm{H}_{2} \mathrm{O}_{2}$ e Fe(II), tendência contrária ao que seria de esperar, o que poderá estar associado a algum erro experimental.

Tabela 2 - Efeito das concentrações de $\mathrm{H}_{2} \mathrm{O}_{2}$ e $\mathrm{Fe}(\mathrm{II})$ na remoção de DQO; períodos de reação /decantação 20/30 minutos $\left(\mathrm{H}_{2} \mathrm{O}_{2}: \mathrm{Fe}(\mathrm{II})=10,9\right)$

\begin{tabular}{ccccc}
\hline Experiência & $\mathrm{pH}$ & $\mathrm{H}_{2} \mathrm{O}_{2}(\mathrm{~g} / \mathrm{L})$ & $\mathrm{Fe}^{2+}(\mathrm{g} / \mathrm{L})$ & Remoção DQO (\%) \\
\hline 1 & 2,5 & 4,5 & 0,41 & 35,1 \\
$1 \mathrm{a}$ & 2,5 & 6,0 & 0,55 & 28,5 \\
& & & & 29,8 \\
2 & 3,0 & 4,5 & 0,41 & 29,8 \\
$2 \mathrm{a}$ & 3,0 & 6,0 & 0,55 & 25,8 \\
& & 4,5 & & 25,8 \\
$3 \mathrm{a}$ & 3,5 & 6,0 & 0,41 & \\
\hline
\end{tabular}

Avaliação do efeito da dosagem de peróxido de hidrogénio e de sulfato de ferro sobre a remoção de DQO: Realizaram-se dois conjuntos de experiências a $\mathrm{pH}$ 2,5: i) avaliar o efeito da variação da concentração de $\mathrm{H}_{2} \mathrm{O}_{2}$ na gama 3 a $12 \mathrm{~g} / \mathrm{L}$, e concentração de $\mathrm{Fe}(\mathrm{II})$ constante $(0,55 \mathrm{~g} / \mathrm{L})$; ii) concentração de $\mathrm{Fe}(\mathrm{II})$ variável $(0,55$ a $2,18 \mathrm{~g} / \mathrm{L})$, mantendo constante a concentração de $\mathrm{H}_{2} \mathrm{O}_{2}(12$ 
g/L). Os resultados obtidos são apresentados nas Tabelas 3 e 4.

Tabela 3 - Efeito da dosagem de $\mathrm{H}_{2} \mathrm{O}_{2}\left(\left[\mathrm{Fe}(\mathrm{II}]=0,55 \mathrm{~g} / \mathrm{L} ; \mathrm{DQO}_{\text {inicial }}=6450 \mathrm{mg} \mathrm{O} / \mathrm{L}\right)\right.$ na remoção da Demanda Química de Oxigénio

\begin{tabular}{lcccccc}
\hline Parâmetro & \multicolumn{7}{c}{ Experiência } \\
& 1 & 2 & 3 & 4 & 5 & 6 \\
\hline $\mathrm{H}_{2} \mathrm{O}_{2}(\mathrm{~g} / \mathrm{L})$ & 3 & 4,5 & 6 & 7,5 & 9 & 12 \\
$\mathrm{H}_{2} \mathrm{O}_{2}: \mathrm{Fe}(\mathrm{II})$ & 5,5 & 8,2 & 10,9 & 13,6 & 16,4 & 21,8 \\
$\mathrm{DQO}$ final $\left(\mathrm{mg} \mathrm{O}_{2} / \mathrm{L}\right)$ & 3964 & 3900 & 3980 & 3741 & 3582 & 3235 \\
Remoção DQO $(\%)$ & 38,5 & 39,5 & 38,3 & 42,0 & 44,5 & 49,8 \\
\hline
\end{tabular}

Tabela 4 - Efeito da dosagem de Fe(II) $\left(\left[\mathrm{H}_{2} \mathrm{O}_{2}\right]=12 \mathrm{~g} / \mathrm{L}\right.$; DQO $\left.\mathrm{Dinial}_{\text {la }}=6450 \mathrm{mg} \mathrm{O} 2 / \mathrm{L}\right)$ na remoção da Demanda Química de Oxigénio

\begin{tabular}{lcccccc}
\hline Parâmetro & \multicolumn{7}{c}{ Experiência } \\
& 1 & 2 & 3 & 4 & 5 & 6 \\
\hline $\mathrm{Fe}(\mathrm{II})(\mathrm{g} / \mathrm{L})$ & 2,18 & 1,46 & 1,09 & 0,87 & 0,73 & 0,55 \\
$\mathrm{H}_{2} \mathrm{O}_{2}: \mathrm{Fe}(\mathrm{II})$ & 5,5 & 8,2 & 11,0 & 13,8 & 16,4 & 21,8 \\
$\mathrm{DQO}$ final $\left(\mathrm{mg} \mathrm{O}_{2} / \mathrm{L}\right)$ & 2465 & 2545 & 2704 & 2545 & 2863 & 3181 \\
Remoção DQO $(\%)$ & 61,8 & 60,5 & 58,1 & 60,5 & 55,6 & 50,7 \\
\hline
\end{tabular}

Uma análise aos resultados das Tabelas 3 e 4 permite concluir que a remoção de DQO do lixiviado teve um aumento significativo (cerca de 20\%) com a concentração de Fe(II) de 0,55 para $0,87 \mathrm{~g} / \mathrm{L}$, permanecendo depois praticamente constante no restante intervalo de concentrações estudadas. Observou-se assim, que a combinação de $12 \mathrm{~g} / \mathrm{L}$ de $\mathrm{H}_{2} \mathrm{O}_{2}$ com 0,87 g/L de $\mathrm{Fe}(\mathrm{II})$, para um $\mathrm{pH}$ inicial de 2,5 , e à temperatura de $25^{\circ} \mathrm{C}$, permitiu alcançar uma remoção de DQO próxima de $61 \%$. Atendendo às concentrações de oxidante e catalisador usadas a razão $\mathrm{H}_{2} \mathrm{O}_{2}: \mathrm{Fe}(\mathrm{II})$ é de aproximadamente 13,8, ou seja corresponde à utilização de uma razão molar de 22,7.

\subsection{Produção de Lama - Reação de Oxidação com o Reagente de Fenton}

No tratamento do lixiviado pelo processo Fenton é gerado um volume de lama, que depende da razão $\mathrm{H}_{2} \mathrm{O}_{2}$ : $\mathrm{Fe}(\mathrm{II})$ utilizada. A Figura 4 apresenta o volume de lama gerada, após um período de decantação de 30 minutos e utilizando diferentes razões de $\mathrm{H}_{2} \mathrm{O}_{2}: \mathrm{Fe}(\mathrm{II})$. Nos ensaios a concentração de $\mathrm{Fe}(\mathrm{II})$ foi mantida constante $(0,55 \mathrm{~g} / \mathrm{L})$, enquanto a $\left[\mathrm{H}_{2} \mathrm{O}_{2}\right]$ variou na gama $3-12 \mathrm{~g} / \mathrm{L}(\mathrm{pH}$ e temperatura foram os habituais).

Para uma razão crescente de $\mathrm{H}_{2} \mathrm{O}_{2}: \mathrm{Fe}(\mathrm{II})$ correspondeu a formação de um menor volume de lama, o que pode ser devido a uma maior conversão de $\mathrm{Fe}(\mathrm{III})$ a $\mathrm{Fe}$ (II). Dependendo da razão $\mathrm{H}_{2} \mathrm{O}_{2}: \mathrm{Fe}$ (II) usada, para a gama estudada, corresponderia a uma produção de lamas entre os 230 e os $60 \mathrm{~L}$ de lama $/ \mathrm{m}^{3}$ de lixiviado. 


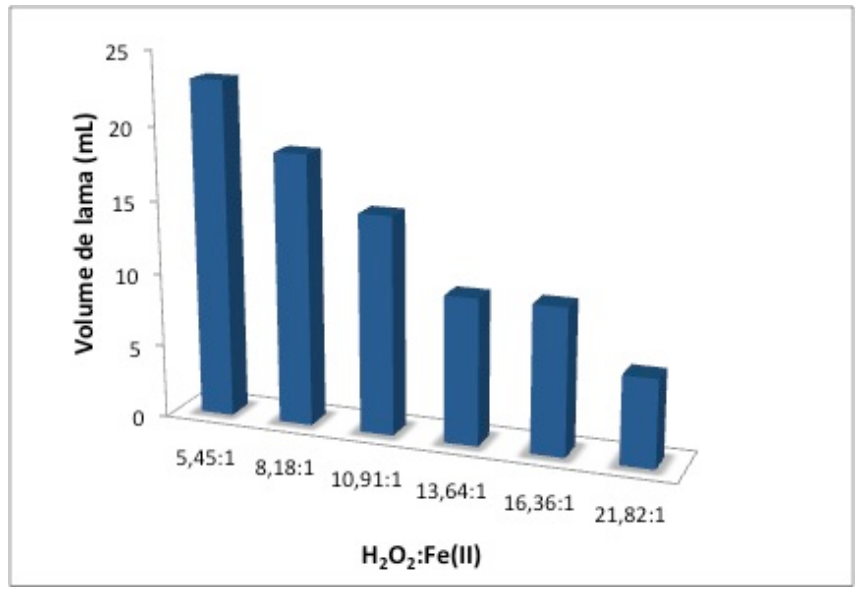

Figura 4 - Produção de lama em função da razão $\mathrm{H}_{2} \mathrm{O}_{2}: \mathrm{Fe}(\mathrm{II})$; [Fe(II)] constante.

\section{CONCLUSÕES}

O lixiviado apresentou um $\mathrm{pH}$ de 8,7, na gama alcalina. De acordo com a literatura este valor é atribuído a um lixiviado resultante de um aterro antigo, e que se encontra numa fase metanogénica, o que contraria realidade do aterro. Embora o lixiviado seja proveniente de um aterro novo, provavelmente encontra-se já na fase metanogénica, a mais ativa biologicamente.

Nas experiências realizadas, com o reagente de Fenton, o tempo de reação ótimo foi de 20 minutos, e o período de decantação de 30 minutos, a que correspondeu a maior remoção de DQO.

Após o período de reação a temperatura aumentou para um valor próximo de $33^{\circ} \mathrm{C}$; a reação é exotérmica como era esperado.

Relativamente ao efeito do $\mathrm{pH}$, conclui-se que a remoção de DQO aumenta com a razão $\mathrm{H}_{2} \mathrm{O}_{2}$ : $\mathrm{Fe}$ (II), embora o efeito do $\mathrm{pH}$ na gama de 2,5-3,5 não tenha sido tão significativo. A pH 2,5 foi obtida a maior remoção de DQO (64,3\%).

A remoção de DQO aumenta significativamente com a concentração de $\mathrm{Fe}$ (II) de 0,55 para 0,87 $\mathrm{g} / \mathrm{L}$, mantendo-se depois praticamente constante e a combinação de $12 \mathrm{~g} / \mathrm{L} \mathrm{de} \mathrm{H}_{2} \mathrm{O}_{2}$ com $0,87 \mathrm{~g} / \mathrm{L}$ de $\mathrm{Fe}(\mathrm{II})$, conduz a uma boa remoção, aproximadamente $62 \%$.

A quantidade de lama gerada no processo Fenton foi maior para a menor dosagem de peróxido, consequentemente com menor razão $\mathrm{H}_{2} \mathrm{O}_{2}: \mathrm{Fe}(\mathrm{II})$.

O estudo cinético permite concluir que após cerca de 3 segundos de reação a DQO reduz-se mais de $50 \%$, e que para um tempo da ordem dos 40 minutos se atinge uma eficiência de remoção máxima de 65,4\%. O tempo de reação adotado (20 minutos) em todas as experiências realizadas, conduziu a uma eficiência de remoção muito próxima do valor máximo, o que se justifica, por permitir num tratamento em contínuo reduzir o volume do reator por $\mathrm{m}^{3}$ de caudal a tratar. 


\section{REFERÊNCIAS}

ALLEN, A. Sustainable landfilling for developing countries. Ninth International Waste Management and Landfill Symposium, Cagliari, 2003.

APHA. Standard Methods for the Examination of Water and Wastewater. Washington DC: 22 Ed., 2012.

DING, Z.; GUAN, W. Treatment of landfill leachate by microwave-fenton oxidation process catalysed by $\mathrm{Fe}^{2+}$ loaded GAC. J. Testing and Eval., v 41, p. 2012-2018, 2013.

EEA - Europe's Environment: the second assessment. Elsevier Science Ltd, 293 p, 1998.

GOI, A.; VERESSININA, Y.; TRAPIDO, M. Fenton process for landfill leachate treatment: evaluation of biodegradability and toxicity. J. Environ. Eng., v 136(1), p. 46-53, 2010.

LIMA, W. S. Avaliação do desempenho de remoção de poluentes de lixiviados: um estudo de caso para o sistema de tratamento do Aterro Municipal de Betim- Minas Gerais. Belo Horizonte: Tese de mestrado, UFMG, 2006.

METCALF \& EDDY INC. Wastewater Engineering: Treatment and Reuse. New York: McGrawHill, 4 Ed., 2003.

SILVA, C. E.; LANGE, L. C.; FERREIRA, C. F. A.; AMARAL, M. C. S. Avaliação da composição orgânica de percolado submetido aos processos Fenton e Foto-Fenton. $30^{\circ}$ Congresso Interamericano de Engenharia Sanitária e Ambiental-AIDIS, Punta Del Leste, 2006. 